\title{
Evaluation of various soaking agents as a novel tool for heavy metal residues mitigation from spinach
}

\author{
Rai Muhammad AMIR ${ }^{1 \star}$, Muhammad Atif RANDHAWA², Muhammad Wasim SAJID ${ }^{3}$, Muhammad NADEEM ${ }^{4}$, \\ Anwaar $\mathrm{AHMAD}^{1}$, Fahad Masoud WATTOO ${ }^{5}$
}

\begin{abstract}
Heavy metals pollution is a global threat to the environment and ecosystem due to various human and natural activities. Heavy metal intake through vegetables and diet leads to numerous ailments such as nervous disorder, kidney damage tubular growth and bone disease. The present study was conducted to mitigate the residue of heavy metals $\mathrm{Hg}, \mathrm{Pb}, \mathrm{Zn}$ and As in spinach collected from self-grown supervised field by using different washing treatments. Amount of trace metals was measured in fresh and chemically washed spinach samples with the help of Atomic Absorption Spectrophotometer (AAS). Results revealed that highest reduction of mercury, lead, zinc and arsenic residues with $10 \%$ citric acid was $23 \%, 28 \%, 54 \%$ and $22 \%$ respectively among the tested solutions. However, tap water treatment also reduced $7 \%, 7 \%, 15 \%$ and 6 , respectively. Among various washing solutions citric acid proved maximum reduction potential followed by Lemon extract, sodium carbonate, reddish extract and hydrogen peroxide respectively. The percent reduction by various solutions ranged from 7 to $23 \%, 7$ to $28 \%, 15$ to $54 \%$ and 6 to $22 \%$ for elimination of mercury, lead, zinc and arsenic, respectively. More reduction was found in zinc followed lead, mercury and arsenic.
\end{abstract}

Keywords: heavy metals; spinach; wastewater; acidic solutions; alkaline solutions; biological extract.

Practical Application: Washing solutions citric acid, lemon extract, sodium carbonate, reddish extract and hydrogen peroxide can be used to mitigate heavy metal residues in vegetables.

\section{Introduction}

Agriculture is the backbone of Pakistan that is blessed with plentiful natural resources such as fertile and productive soil, better water irrigation system and climate change from tropical to temperate. From last few years due to shortage of water availability, the use of sewage water has increased tremendously, especially in semiarid region of Pakistan. Vegetables are the valuable source of different ingredients that play a vital role for the prevention of various ailments, maintaining alkaline reserve of the body, repair the body organ and protect human health (Dalal et al., 2006; Marwa et al., 2009). Among different vegetables, spinach is a short duration crop mostly grow in subtropical region with significant mineral profile, upon consumption it provides macro and micronutrients to the body (Bangash et al., 2011).

Heavy metal contamination mainly occurs due the application of use of metal-based pesticides, waste water irrigation, fertilizers, emission and transportation of industrial waste on crops (Agrawal \& Marshall, 2003). Soil contamination due to increasing concentration of heavy metals is becoming a very serious problem to environment (Bhutto et al., 2009). In soil, waste water is single largest contributor of heavy metal contents because these effluents are heavily loaded with metallic compounds and ultimately vegetables consumption pose serious threat to human health (Singh et al., 2004; Mapanda et al., 2005; Sharma et al., 2004).

Traditional washing techniques are used to remove waste, dust, dirt and filth prior to use vegetables and they are considered vital tool for the reduction of heavy metals residues. Strong acid, ozonated water and bleach solution has been found successful for mitigation of heavy metal and other chemical residues. Tap water washing for 2-3 times reduced significant amount of heavy metal such as lead and cadmium from $75-100 \%$ and $27-55 \%$ for copper and zinc in vegetables (Singh \& Kumar, 2006).

Heavy metal residues and other particles deposited on the surface of vegetables removes significantly by simple washing (Sharma et al., 2008). In spinach, heavy metal such as $\mathrm{Pb}, \mathrm{Cd}$, $\mathrm{Cr}$ and $\mathrm{Zn}$ reduced at $21 \%, 21 \%, 13 \%$ and $26 \%$ respectively, by simple washing. In coriander, heavy metal reduction was found $11 \%, 31 \%, 11 \%, 5 \%$ and $6 \%$ for $\mathrm{Cd}, \mathrm{Pb}, \mathrm{Cr}, \mathrm{Ni}$ and $\mathrm{Zn}$ and for methi reduction pattern $14 \%, 13 \%, 15 \%, 17 \%$ and $13 \%$, respectively (Suruchi \& Jilani, 2011).

Increasing concentration of heavy metal residues in soil, water and foodstuff is a distressing phenomenon around the world. The pollution of water and soil directly linked with food 
chain contamination through irrigation. European Union and United States has already set up strict limits for various heavy metals in water, but current food legislation does not have legal limits for a number of heavy metals in food and this fact causes considerable health hazards to babies, children, pregnant women and all other consumers. Keeping in view the potential toxic effects of heavy metal residues as a result of vegetable consumption, recent project was designed to elucidate heavy metals residues in spinach to explore the effectiveness of various soaking agents to reduce heavy metal residues.

\section{Materials and methods}

\subsection{Procurement of raw materials}

Spinach (Spinacia oleracea L.) was grown in the experimental field of University of Agriculture Faisalabad, Pakistan. For irrigation purpose sewage water was applied. One kg sample of spinach was obtained at the point of optimum maturity at triplicate form from different locations of the plot. The samples were instantly shifted to the labortary of National Institute of Food Science and Technology, University of Agriculture Faisalabad, Pakistan for subsequent analysis of samples.

\subsection{Application of washing solutions to treated spinach samples}

The collected spinach samples were reduced to appropriate size by using knife to facilitate the analysis. The study was designed with different washing treatments by using tap water and following concentrations of chemical, alkaline and biological solutions along with one unwashed sample shown in Table 1.

After solution preparation spinach samples were soaked in solution for ten minutes at $30^{\circ} \mathrm{C}$ for washing purpose. The washed spinach samples were blended by using commercial blender to consistent paste of pulp and juice. Spinach samples in three replicates of each washing technique were kept in hot air oven at $70-80{ }^{\circ} \mathrm{C}$ till complete dryness. After drying, vegetable samples were grounded in to fine powder ( 80 mesh) using commercial blender and preserved in polythene bag for further analysis.

Table 1. Different washing treatments.

\begin{tabular}{lcc}
\hline \multicolumn{1}{c}{ Reagents } & Concentrations & Treatments \\
\hline Unwashed & - & $\mathrm{T}_{1}$ \\
Tap water & - & $\mathrm{T}_{2}$ \\
Washing Treatments & & \\
Reddish & $5 \%$ & $\mathrm{~T}_{3}$ \\
& $10 \%$ & $\mathrm{~T}_{4}$ \\
Sodium Carbonate & $5 \%$ & $\mathrm{~T}_{5}$ \\
& $10 \%$ & $\mathrm{~T}_{6}$ \\
Hydrogen Peroxide & $5 \%$ & $\mathrm{~T}_{7}$ \\
& $10 \%$ & $\mathrm{~T}_{8}$ \\
Lemon & $5 \%$ & $\mathrm{~T}_{9}$ \\
& $10 \%$ & $\mathrm{~T}_{10}$ \\
Citric Acid & $5 \%$ & $\mathrm{~T}_{11}$ \\
& $10 \%$ & $\mathrm{~T}_{12}$ \\
\hline
\end{tabular}

\subsection{Sample digestion}

The grounded spinach sample (0.5-1.0) was placed in to Pyrex beaker, added $10 \mathrm{~mL}$ of concentrated $\mathrm{HNO}_{3}$ to it and kept for night without heating. Then it was heated on hot plate near to dryness, cooled and add $5 \mathrm{~mL}$ of $\mathrm{HCLO}_{4}$ and again heated till digestion was completed, then digested sample was filtered in to clean volumetric flask and diluted to $50 \mathrm{~mL}$ with deionized water (Nwajei, 2009).

\subsection{Preparation of standards}

The standard solutions (5, 10,15 and $20 \mathrm{ppm})$ of all the metals $(\mathrm{Hg}, \mathrm{Pb} \mathrm{Zn}$ and $\mathrm{As})$ were prepared from the stock solutions of $1000 \mathrm{ppm}$ in distilled water.

\subsection{Quantification of heavy metals through atomic absorption spectrophotometer}

The heavy metals $\mathrm{Hg}, \mathrm{Pb}, \mathrm{Zn}$ and As in unwashed, tape water, chemically washed, dried and digested spinach samples were determined by using Varian GTA 120 AA 240 Graphite Atomic Absorption Spectrophotometer (Horwitz, 2006). The data obtained was analyzed and represented using standard statistical procedures i.e. completely randomized design (CRD) as described by (Steel et al., 1997).

\section{Results}

The concentrations of mercury, lead, zinc and arsenic were analyzed in different samples of spinach collected from supervised field at the stage of optimum maturity. The results regarding these heavy metals concentration in spinach showed significant variation and linear reduction of heavy metals as presented in Table 2, 3, 4 and 5, respectively. The concentrations of heavy metals in unwashed spinach samples were higher than samples subjected to different washing treatments. The result

Table 2. Mean \pm S.D value and percent reduction of mercury in spinach.

\begin{tabular}{lcc}
\hline \multicolumn{1}{c}{ Treatments } & Mean \pm S.D mg/kg & $\begin{array}{c}\text { Percent } \\
\text { Reduction }(\%)\end{array}$ \\
\hline $\mathrm{T}_{1}$ Unwashed & $0.0481 \pm 0.00081^{\mathrm{a}}$ & \\
$\mathrm{T}_{2}$ Tap water washed & $0.0447 \pm 0.0023^{\mathrm{b}}$ & 7 \\
$\mathrm{~T}_{3}$ Reddish extract 5\% & $0.0436 \pm 0.0016^{\mathrm{bc}}$ & 9 \\
$\mathrm{~T}_{4}$ Reddish extract 10\% & $0.0408 \pm 0.0007^{\mathrm{de}}$ & 15 \\
$\mathrm{~T}_{5}$ Sodium Carbonate 5\% & $0.0429 \pm 0.0013^{\mathrm{bcd}}$ & 11 \\
$\mathrm{~T}_{6}$ Sodium Carbonate 10\% & $0.0399 \pm 0.0008^{\mathrm{ef}}$ & 17 \\
$\mathrm{~T}_{7}$ Hydrogen Peroxide 5\% & $0.0446 \pm 0.0013^{\mathrm{b}}$ & 7 \\
$\mathrm{~T}_{8}$ Hydrogen Peroxide 10\% & $0.0422 \pm 0.0005^{\mathrm{cd}}$ & 12 \\
$\mathrm{~T}_{9}$ Lemon extract 5\% & $0.0429 \pm 0.0017^{\mathrm{bcd}}$ & 11 \\
$\mathrm{~T}_{10}$ Lemon extract 10\% & $0.0374 \pm 0.0019^{\mathrm{f}}$ & 22 \\
$\mathrm{~T}_{11}$ Citric Acid 5\% & $0.0410 \pm 0.0016^{\mathrm{de}}$ & 15 \\
$\mathrm{~T}_{12}$ Citric Acid 10\% & $0.0370 \pm 0.0017^{\mathrm{f}}$ & 23 \\
\hline The letters indicate level of significance between different washing techniques, if same \\
letter then there is no variation.
\end{tabular}


Table 3. Mean \pm S.D value and percent reduction of lead in spinach.

\begin{tabular}{lcc}
\hline \multicolumn{1}{c}{ Treatments } & Mean \pm S.D mg/kg & $\begin{array}{c}\text { Percent } \\
\text { Reduction (\%) }\end{array}$ \\
\hline $\mathrm{T}_{1}$ Unwashed & $0.9838 \pm 0.0055^{\mathrm{a}}$ & \\
$\mathrm{T}_{2}$ Tap water washed & $0.9127 \pm 0.0017^{\mathrm{b}}$ & 7 \\
$\mathrm{~T}_{3}$ Reddish extract 5\% & $0.8638 \pm 0.0039^{\mathrm{d}}$ & 12 \\
$\mathrm{~T}_{4}$ Reddish extract 10\% & $0.8034 \pm 0.0029^{\mathrm{i}}$ & 18 \\
$\mathrm{~T}_{5}$ Sodium Carbonate 5\% & $0.8541 \pm 0.0043^{\mathrm{e}}$ & 13 \\
$\mathrm{~T}_{6}$ Sodium Carbonate 10\% & $0.8235 \pm 0.0032^{\mathrm{g}}$ & 16 \\
$\mathrm{~T}_{7}$ Hydrogen Peroxide 5\% & $0.9035 \pm 0.0037^{\mathrm{c}}$ & 8 \\
$\mathrm{~T}_{8}$ Hydrogen Peroxide 10\% & $0.8548 \pm 0.0012^{\mathrm{e}}$ & 13 \\
$\mathrm{~T}_{9}$ Lemon extract 5\% & $0.8340 \pm 0.0038^{\mathrm{f}}$ & 15 \\
$\mathrm{~T}_{10}$ Lemon extract 10\% & $0.7267 \pm 0.0029^{\mathrm{j}}$ & 26 \\
$\mathrm{~T}_{11}$ Citric Acid 5\% & $0.8121 \pm 0.0105^{\mathrm{h}}$ & 17 \\
$\mathrm{~T}_{12}$ Citric Acid 10\% & $0.7067 \pm 0.0032^{\mathrm{k}}$ & 28 \\
\hline
\end{tabular}

The letters indicate level of significance between different washing techniques, if same letter then there is no variation.

Table 4. Mean \pm S.D value and percent reduction of zinc in spinach.

\begin{tabular}{lcc}
\hline \multicolumn{1}{c}{ Treatments } & Mean \pm S.D mg/kg & $\begin{array}{c}\text { Percent } \\
\text { Reduction (\%) }\end{array}$ \\
\hline $\mathrm{T}_{1}$ Unwashed & $7.4747 \pm 0.0227^{\mathrm{a}}$ & \\
$\mathrm{T}_{2}$ Tap water washed & $6.3577 \pm 0.0220^{\mathrm{b}}$ & 15 \\
$\mathrm{~T}_{3}$ Reddish extract 5\% & $5.8498 \pm 0.0164^{\mathrm{d}}$ & 22 \\
$\mathrm{~T}_{4}$ Reddish extract 10\% & $5.0962 \pm 0.0992^{\mathrm{ef}}$ & 32 \\
$\mathrm{~T}_{5}$ Sodium Carbonate 5\% & $5.9077 \pm 0.0099^{\mathrm{cd}}$ & 21 \\
$\mathrm{~T}_{6}$ Sodium Carbonate 10\% & $4.4114 \pm 0.3785^{\mathrm{h}}$ & 41 \\
$\mathrm{~T}_{7}$ Hydrogen Peroxide 5\% & $6.0669 \pm 0.0296^{\mathrm{c}}$ & 19 \\
$\mathrm{~T}_{8}$ Hydrogen Peroxide 10\% & $5.0091 \pm 0.0003^{\mathrm{fg}}$ & 33 \\
$\mathrm{~T}_{9}$ Lemon extract 5\% & $5.2344 \pm 0.0181^{\mathrm{e}}$ & 30 \\
$\mathrm{~T}_{10}$ Lemon extract 10\% & $3.5816 \pm 0.0362^{\mathrm{i}}$ & 52 \\
$\mathrm{~T}_{11}$ Citric Acid 5\% & $4.8476 \pm 0.0811^{\mathrm{g}}$ & 35 \\
$\mathrm{~T}_{12}$ Citric Acid 10\% & $3.4316 \pm 0.0274^{\mathrm{i}}$ & 54 \\
\hline
\end{tabular}

The letters indicate level of significance between different washing techniques, if same letter then there is no variation.

Table 5. Mean \pm S.D value and percent reduction of arsenic in spinach.

\begin{tabular}{llc}
\hline \multicolumn{1}{c}{ Treatments } & Mean \pm S.D mg/kg & $\begin{array}{c}\text { Percent } \\
\text { Reduction }(\%)\end{array}$ \\
\hline $\mathrm{T}_{1}$ Unwashed & $0.1048 \pm 0.0105^{\mathrm{a}}$ & \\
$\mathrm{T}_{2}$ Tap water washed & $0.0987 \pm 0.0013^{\mathrm{b}}$ & 6 \\
$\mathrm{~T}_{3}$ Reddish extract 5\% & $0.0965 \pm 0.0006^{\mathrm{bcd}}$ & 8 \\
$\mathrm{~T}_{4}$ Reddish extract 10\% & $0.0913 \pm 0.0007^{\text {def }}$ & 13 \\
$\mathrm{~T}_{5}$ Sodium Carbonate 5\% & $0.0976 \pm 0.0005^{\mathrm{bc}}$ & 7 \\
$\mathrm{~T}_{6}$ Sodium Carbonate 10\% & $0.0928 \pm 0.0005^{\text {cdef }}$ & 11 \\
$\mathrm{~T}_{7}$ Hydrogen Peroxide 5\% & $0.0976 \pm 0.0014^{\mathrm{bc}}$ & 7 \\
$\mathrm{~T}_{8}$ Hydrogen Peroxide10\% & $0.0945 \pm 0.0015^{\mathrm{bcde}}$ & 10 \\
$\mathrm{~T}_{9}$ Lemon extract 5\% & $0.0943 \pm 0.0006^{\mathrm{bcde}}$ & 10 \\
$\mathrm{~T}_{10}$ Lemon extract 10\% & $0.0889 \pm 0.0008^{\mathrm{f}}$ & 15 \\
$\mathrm{~T}_{11}$ Citric Acid 5\% & $0.0903 \pm 0.0009^{\mathrm{ef}}$ & 14 \\
$\mathrm{~T}_{12}$ Citric Acid 10\% & $0.0818 \pm 0.0011^{\mathrm{g}}$ & 22 \\
\hline
\end{tabular}

The letters indicate level of significance between different washing techniques, if same letter then there is no variation. regarding mercury showed progressive increase in reduction of residues of mercury with the increase of concentration of treatments (Table 2). Out of all the washing treatments, it was observed that the minimum reduction of mercury residues $7 \%$ was recorded when $\mathrm{T}_{1}$ tap was applied to spinach. The spinach treated with $\mathrm{T}_{12} 10 \%$ citric acid yielded the maximum reduction of mercury which was $23 \%$ followed by lemon extract $22 \%$, sodium carbonate $17 \%$, reddish extract $15 \%$ and hydrogen peroxide $12 \%$. Furthermore, the maximum reduction of lead residues $28 \%$ was observed when $\mathrm{T}_{12} 10 \%$ citric acid was applied to spinach followed by lemon extract $26 \%$, reddish extract 18 , sodium carbonate $16 \%$ and hydrogen peroxide $13 \%$ depicted in Table 3. Similarly, the maximum reduction of zinc residues $54 \%$ was recorded when $\mathrm{T}_{12} 10 \%$ citric acid was applied to spinach followed by lemon extract $52 \%$, sodium carbonate $41 \%$, hydrogen peroxide $33 \%$ and reddish extract $32 \%$ depicted in Table 4. Moreover, spinach treated with $\mathrm{T}_{12} 10 \%$ citric acid yielded the maximum reduction of arsenic which was $22 \%$ followed by lemon extract $15 \%$, reddish extract $13 \%$, sodium carbonate $11 \%$, and hydrogen peroxide $10 \%$ shown in Table 5 . The tap water reduces the mercury, lead, zinc and arsenic contents by $7,7,15$ and $6 \%$ in spinach and $\mathrm{T}_{12} 10 \%$ citric acid was found to be more effective in all the spinach samples to reduce mercury, lead, zinc and arsenic contents.

\section{Discussion}

The results pertaining from the current study reveals that the heavy metal residues declined extraordinary when spinach samples were given washing treatment irrespective to the type of washing, different treatments declined the mercury residues ranges from 7 to $23 \%$, lead 7 to $28 \%$, zinc 15 to $54 \%$ and arsenic 6 to $22 \%$ in spinach. More reduction was found in zinc followed by lead, mercury and arsenic, respectively.

Among all heavy metals zinc exhibited higher mitigation owing to their more dissolving power and physiochemical properties as compared to other heavy metals. During washing operation, variation in reduction of heavy metal residues may be due to their change in the behavior against washing treatments. The treatment of spinach with tap water removes maximum of the heavy metal residues attached to the outer surface of the spinach as well as in the skin of the vegetable due to its dissolving power because that is considered a universal solvent.

The present study results also indicated that citric acid showed maximum reduction of heavy metal residues due its working ability as a chelating agent and resulting made the heavy metal residues unavailable, salt solution sodium carbonate also reduced significant amount of heavy metal residues and biological extract lemon exposed high decrease of heavy metal residues as compared to reddish extract. Acidic washing solutions were more effective in the removal of the zinc, lead, mercury and arsenic under examination than biological extracts and salt solutions.

Vegetables are the valuable source of different ingredients that play a vital role for maintaining the nutritional status of humans and prevention of various ailments, maintaining alkaline reserve of the body, repair the body organ and assure healthy human life. Heavy metals accumulation in the vegetables take place usually 
from soil, water and atmosphere. Vegetables intake affected with heavy metals leads to several disorders including nervous disorder, kidney damage, bone diseases and several tubular growths. Uptake of these metals in vegetables from polluted soil by absorbing them as well as from deposits on the exposed vegetable region through air in the prevailing polluted environments.

The results of the recent research are in conformity with previous results of Krol et al. (2000) who also observed residues of cadmium and lead were reduced during washing treatment in vegetables.

The findings of the present study are in line of Parveen et al. (2003) who determined the concentration of cadmium in unwashed vegetables. Reduction pattern of cadmium in this study was similar to the investigation that was carried out by Singh \& Kumar (2006) to estimate the heavy metal load of unwashed and washed vegetables in peri-urban, Delhi. In addition, Suruchi \& Jilani (2011) also reported the same reduction pattern of cadmium in spinach, okra and brinjal, open to different levels of pollution in the city of India i.e Agra, by washing treatment given with tape water. The arsenic is a toxic element and the humans may get exposure to arsenic through drinking water obtained by wells bored into arsenic contaminated areas or through contaminated water by agro-chemical waste or industrial effluents. The results of the present study regarding arsenic in spinach are similar with the findings of Al-Chaarani et al. (2009). Higher level of lead contents than the recommended $\left(0.2 \mu \mathrm{gg}^{-1}\right)$ in humans, causes teeth and blood diseases, weak bones, kidney damage, defects in reproductive system, increased pancreas weight, affects liver, cardiovascular and peripheral nervous system. The results of the present study regarding the lead concentration in normal treatment of vegetables have shown the same results as mentioned by Naser et al. (2009) to estimate concentration of different heavy metals in vegetables. Lead reduction by tap water washing follows the same pattern as reported by the Singh \& Kumar (2006) to estimate the different heavy metal contents from unwashed and washed vegetables collected from peri urban region of Delhi. In past, maximum level $\left(0.02 \mu \mathrm{gg}^{-1}\right)$ of mercury was observed in fenugreek/methi i.e. leafy vegetables while minimum level $\left(0.001 \mu g g^{-1}\right)$ were reported in root/tuberous vegetables whereas high contents of arsenic $\left(0.083 \mu \mathrm{gg}^{-1}\right)$ was observed in fruity vegetables (okra), on the other hand minimum level $\left(0.014 \mu \mathrm{gg}^{-1}\right)$ was reported in cauliflower (Nergus et al., 2005).

Traditional washing techniques are used to remove waste, dust and dirt before using vegetables and they are expressed as vital tool for reducing heavy metals residues. Washing tap water for 2-3 times reduced significant amount of heavy metal such as lead and cadmium from $75-100 \%$ and $27-55 \%$ for copper and zinc in vegetables (Singh \& Kumar, 2006).

Finding of the recent study are parallel to the investigation of Sharma et al. (2008) who reported that significant removal of excess heavy metal contents and other particles deposited on the surface of vegetables by simple washing. In spinach, heavy metal such as $\mathrm{Pb}, \mathrm{Cd}, \mathrm{Cr}$ and $\mathrm{Zn}$ reduced at $21 \%, 21 \%, 13 \%$ and $26 \%$ respectively, by simple washing. In coriander, heavy metal reduction was found $11 \%, 31 \%, 11 \%, 5 \%$ and $6 \%$ for $\mathrm{Cd}, \mathrm{Pb}$, $\mathrm{Cr}, \mathrm{Ni}$ and $\mathrm{Zn}$ and regarding leafy vegetable i.e methi reduction figures were $14 \%, 13 \%, 15 \%, 17 \%$ and $13 \%$, respectively (Suruchi \& Jilani, 2011).

\section{Conclusions}

Spinach samples were contaminated with different heavy metal residues and wastewater irrigation is the sole and important source of heavy metals contamination in soil as well as in vegetables. Due to large surface area, spinach shows higher deposition of different heavy metals and tap water and household chemicals solutions washing significantly decrease dust, dirt, debris and heavy metal residues. These different washing techniques mechanically clear the heavy metals adhered on the surface of the spinach which mostly accumulate through aerial deposition. As an outcome of this study, it is highly recommended that vegetables must not be grown with sewerage water and at kitchen gardening level the vegetables must be treated with tap water moreover washing treatments including citric acid, hydrogen peroxide, sodium carbonate and biological extracts of lemon and radish are useful in the reduction of heavy metal residues. These methods are very simple because they can easily perform at local conditions and beneficial due their working ability to mitigate the metal residues.

\section{Acknowledgements}

The authors would like to express sincere gratitude for the financial support provided by Panjab Agricultural Research Board.

\section{References}

Agrawal, M., \& Marshall, F. M. (2003). Heavy metals contamination in vegetables grown in wastewater irrigation areas of Varanasi, India. Bulletin of Environmental Contamination and Toxicology, 77, 311-318.

Al-Chaarani, N., El-Nakat, J. H., Obeid, P. J., \& Aouad, S. (2009). Measurement of levels of heavy metal contamination in vegetables grown and sold in selected areas in Lebanon. Jordan Journal of Chemistry, 4(3), 303-315.

Bangash, J. A., Arif, M., Khan, M., \& Hussain, I. K. F. (2011). Proximate composition, minerals and vitamins content of selected vegetables grown in Peshawar. Journal of the Chemical Society of Pakistan, 33, 118-122.

Bhutto, M. A., Zahida, P., Riazuddin, S. I., Mubarik, A., \& Sahar, N. (2009). Monitoring of heavy and essential trace metals in wheat procured form various countries. International Journal of Biology and Biotechnology, 6, 247-256.

Dalal, M., Dani, R. G., \& Kumar, P. A. (2006). Current trends in the genetic engineering of vegetable crops. Scientia Horticulturae, 107(3), 215-225. http://dx.doi.org/10.1016/j.scienta.2005.10.004.

Horwitz, W. (2006). Official methods of analysis of association of official analytical chemists international (18th ed.). Arlington: AOAC.

Krol, W. J., Arsenault, T. L., Pylypiw, H. M. Jr., \& Incorvia Mattina, M. J. (2000). Reduction of pesticide residues on produce by rinsing. Journal of Agricultural and Food Chemistry, 48(10), 4666-4670. http://dx.doi.org/10.1021/jf0002894. PMid:11052716.

Mapanda, F., Mangwayana, E. N., Nyamangara, J., \& Giller, K. E. (2005). The effect of long-term irrigation using wastewater on heavy metal contents of soils under vegetables in Harare, Zimbabwe. Agriculture, Ecosystems \& Environment, 107(2), 151-165. http:// dx.doi.org/10.1016/j.agee.2004.11.005.

Marwa, S. K., Khan, M. A., Khan, M. A., Ahmad, M., Zafar, M., urRehman, F., \& Sultana, S. (2009). Vegetables mentioned in the Holy Qura'n and Ahadith and their ethnomedicinal studies in Dera Ismail 
Khan, NWFP, Pakistan. Pakistan Journal of Nutrition, 8(5), 530-538. http://dx.doi.org/10.3923/pjn.2009.530.538.

Naser, H. M., Shil, N. C., Rashid, N. U. M., \& Hossain, K. M. (2009). Lead, cadmium and nickel contents of vegetables grown in industrially polluted and non-polluted areas of Bangladesh. Bangladesh Journal of Agricultural Research, 34, 545-554.

Nergus, Y., Ahmed, S. I., \& Sharif, M. (2005). Impact of contaminated vegetables, fruits and fodders on human health by Malir River farms Karachi. Journal of the Chemical Society of Pakistan, 27(6), 561-571.

Nwajei, G. E. (2009). Trace elements in soils and vegetations in the vicinity of shell petroleum development company operating area in Ughelli, delta state of Nigeria. American-Eurasian Journal of Sustainable Agriculture, 3(3), 574-578.

Parveen, Z., Khuhro, M. I., \& Rafiq, N. (2003). Market basket survey for lead, cadmium, copper, chromium, nickel, and zinc in fruits and vegetables. Bulletin of Environmental Contamination and Toxicology, 71(6), 1260-1264. http://dx.doi.org/10.1007/s00128-003-8640-4. PMid:14756297.

Sharma, O. P., Bangar, K. S., Jain, R., \& Sharma, P. K. (2004). Heavy metals accumulation in soils irrigated by municipal and industrial effluent. Journal of Environmental Science \& Engineering, 46(1), 65-73. PMid:16649595.
Sharma, R. K., Agrawal, M., \& Marshall, F. M. (2008). Heavy metal $(\mathrm{Cu}, \mathrm{Zn}, \mathrm{Cd}$ and $\mathrm{Pb})$ contamination of vegetables in urban India: a case study in Varanasi. Environmental Pollution, 154(2), 254-263. http://dx.doi.org/10.1016/j.envpol.2007.10.010. PMid: 18031880 .

Singh, K. P., Mohan, D., Sinha, S., \& Dalwani, R. (2004). Impact assessment of treated/untreated wastewater toxicants discharged by sewage treatment plants on health, agricultural, and environmental quality in the wastewater disposal area. Chemosphere, 55(2), 227-255. http://dx.doi.org/10.1016/j.chemosphere.2003.10.050. PMid:14761695.

Singh, S., \& Kumar, M. (2006). Heavy metal load of soil, water and vegetables in peri-urban Delhi. Environmental Monitoring and Assessment, 120(1-3), 79-91. http://dx.doi.org/10.1007/s10661-0059050-3. PMid:16897527.

Steel, R. G. D., Torrie, J. H., \& Dickey, D. A. (1997). Principles and procedures of statistics: a biometrical approach (3rd ed.). New York: McGraw Hill Book.

Suruchi, K., \& Jilani, A. (2011). Assessment of heavy metal concentration in washed and unwashed vegetables exposed to different degrees of pollution in Agra, India. Electronic Journal of Environmental, Agricultural and Food Chemistry, 10(8), 2700-2710. 